\title{
Spinal management: reflections and thoughts
}

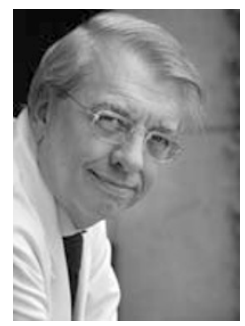

\author{
JJ Wyndaele \\ Antwerp University Hospital, Antwerp, Belgium \\ E-mail: spinalcord@uza.be
}

Dear Spinal Cord reader,

We from the Editorial Office in Antwerp, wish you and yours a wonderful 2011. We welcome the new President of the International Spinal Cord Society (ISCoS), Professor Biering-Sørensen, under whose guidance the Society will progress over the next two years. The first three issues of Spinal Cord published in 2011 will contain double the number of papers. The submissions are impressive in quality and quantity and, as much as possible, we are trying to avoid delaying print publication.

In 2011, ISCoS is celebrating its 50th anniversary year. Therefore I decided to include in this New Year's Editorial Page some reflections of a well known paraplegist, Dr Paul Dollfus, which he wrote at my invitation. He was there from the start: 'I was a young doctor, in June 1960, when I first visited the National Spinal Cord Injury Centre at Stoke Mandeville, directed by Dr Ludwig Guttmann. He, and his co-workers (Jack Walsh, Lorie Michaelis, Hans Frankel, Joseph Melzac, John Silver, and many of the staff) introduced me to the very special care of spinal cord victims. Back in France, my boss told me to create an acute spinal cord unit which was unknown in that region at that time. When asked in the long corridors what the role of a 'paraplegist' was, I answered: 'To be a medical diplomat, Sir'. I had to learn how to deal with very acute patients, at any time after injury, and at the same time to cope with the other doctors, the paramedicals, and the patient's family. Sometimes the police and the emergency first aid teams were a big help in providing some precious information. The examinations were difficult to assess as the patients were very often in a state of shock, sometimes unconscious. The pin prick method (Paraplegia 1986; 24: 343-3495) in suspected tetraplegic patients was a useful tool when they could not answer our questions, did not speak our language or had been intubated at the site of the accident. Medical observation of the victim in the emergency room (why has this been forgotten nowadays?), is quite possible: spontaneous movements especially of upper limbs, breathing, and more. Even rapid sensory evaluation is, in some circumstances, possible. If the patient is unconscious a rapid assessment, helped by a bilateral autonomic 'skin ray' can confirm the level below T2-3.The rest will follow: classical sensory and motor and reflex examinations. They have to be repeated and should therefore be done rather quickly before other examinations (X-ray, SEP, MEP, etc.) are performed and before the neurosurgeon on call, comes into play. Never try and shake the hand (to say hello) of a tetraplegic patient as in a high lesion, he or she will not feel it! Medical observation is the first key to understanding what is going on. One must not forget that a spinal cord victim is usually completely dismayed by what has happened; the family (or friends, employers or teachers) cannot understand what has really happened either.

If awake, the victim will try and ask everybody what has happened and why she or he is paralyzed. It is much better not to be over optimistic nor bluntly negative. The best is to explain the lesion and that in fact there is a need to wait a few weeks or two-three months before a more realistic prognosis can be given. To our surprise most of the patients accepted waiting that long. Tackling the family is quite a different problem. I usually asked them to see the patient first and then I talked to them and gave them gradually a provisional prognosis.'

With these reflections Paul Dollfus has created a good image of what went on in his time and still goes on now, in one way or another, around the world.

The editorial group of Spinal Cord and Nature Publishing Group will do their best to further improve the journal Spinal Cord, 'the Voice of the Spinal Cord'. Do not hesitate to contact us with suggestions and to propose reviewers.

On this occasion at the beginning of the year I also want to thank all who have helped and will help to make Spinal Cord a reference journal for spinal cord care and research: the reviewers, the assistant editors, the editorial board, and the authors who send us their excellent papers. Let us continue working together. 